\title{
Secretory Carcinoma of the Breast
}

\author{
Fatma Aktepe, Dauren Sarsenov, Vahit Özmen \\ Florence Nightingale Hospital, The Breast Center, İstanbul, Turkey
}

\begin{abstract}
Secretory carcinoma is a very rare subtype of breast carcinoma. These tumors are generally associated with a favorable prognosis, although having triple-negative phenotype (estrogen receptor (ER), progesterone receptor (PR) negative and c-erbB2 (HER2) negative). In this presentation, a rare secretory carcinoma of the breast in a woman aged 24 years is discussed and the literature is reviewed.
\end{abstract}

Keywords: Secretory carcinoma, breast, immunohistochemistry

\section{Introduction}

Secretory carcinoma is a very rare histologic type of breast carcinoma that is seen in less than $1 \%$ of invasive breast cancers (1). It was first described by McDivitt and Stewart (2). This tumor is frequently seen in children and adolescents, which is why it is known as "juvenile carcinoma." It is less frequently seen in the elderly population. It has typical histomorphologic features. In general, despite having triplenegative molecular phenotype, it has a favorable prognosis. Very rare cases have been shown to metastasize (3).

\section{Case Presentation}

A woman aged 24 years was evaluated in an external center. Breast ultrasonography (USG) and magnetic resonance imaging (MRI) revealed an 11-mm sized irregular-shaped solid mass with increased vascularization that suspicious for malignancy located at the 9 o'clock position. A biopsy was performed, which revealed secretory carcinoma of the breast. Further assessment in our center resulted in a segmental mastectomy with sentinel lymph node biopsy for right axilla.

Macroscopically, the specimen was $14 \mathrm{~g}$ in weight and 7x6x4-cm-sized lumpectomy material. Serial sections revealed the presence of a nodule measuring $2 \times 2 \times 1.5 \mathrm{~cm}$. It was well-circumscribed, grayish-white, rounded, and lobulated. At the inferior of the lesion, there was another mass. It was fairly irregular, gray-white in color, and $0.9 \times 0.8 \times 0.8 \mathrm{~cm}$ in size.

Microscopic examination revealed a large nodule that was diagnosed as a fibroadenoma (Figure 1). The second lesion drew our attention because of its invasive nature. The tumor comprised microcysts and glandular structures that contained secretory material in their lumens (Figure 2). At high magnification, the tumor cells were mostly bland looking with round and oval nuclei. Immunohistochemistry with epithelial membrane antigen (EMA) and S-100 was performed, which resulted in strong positive staining of the tumor cells (Figure 3, 4). Immunostaining for ER was approximately 3\% positive of the invasive tumor cells (Figure 5), whereas PR and HER2 were negative. The Ki67 proliferation index was found as 3\%. Based on histomorphologic and immunohistochemical features, the diagnosis of secretory carcinoma was approved.

\section{Discussion and Conclusion}

Secretory carcinoma is a rare breast carcinoma and is generally seen in children and young adults $(1,2)$. Although it is seen in children and young adults, it has also been reported in elderly patients (4). Our patient was 24 years old. This carcinoma is also seen in males and has 


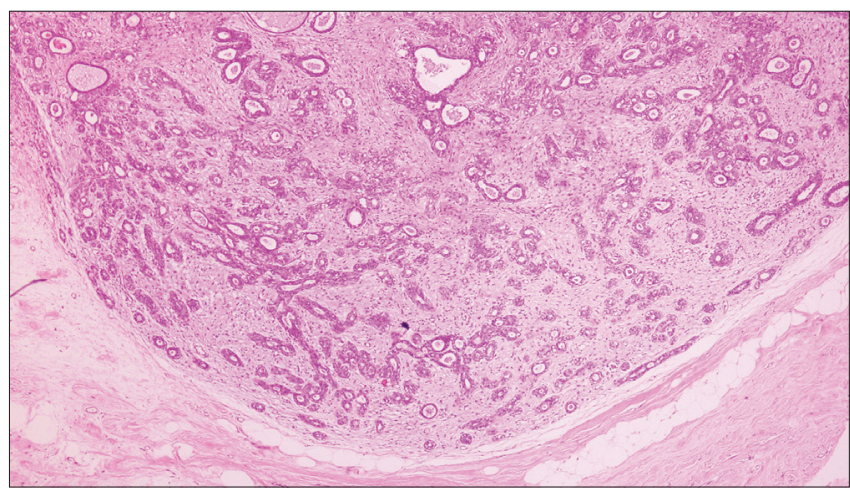

Figure 1. Microscopic view of the fibroadenoma $(H \& E, x 100)$

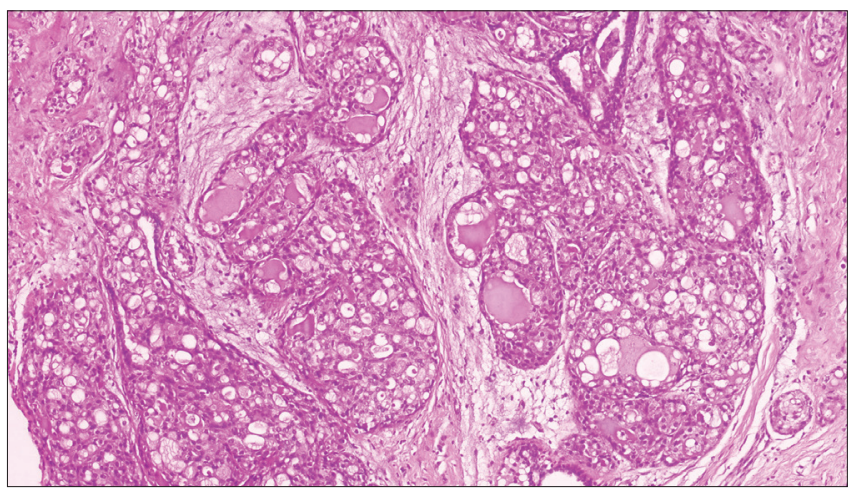

Figure 2. Microcystic and adenoid structures with eosinophilic secretion within the lumen comprising wide cytoplasm cells (H\&E, X200)

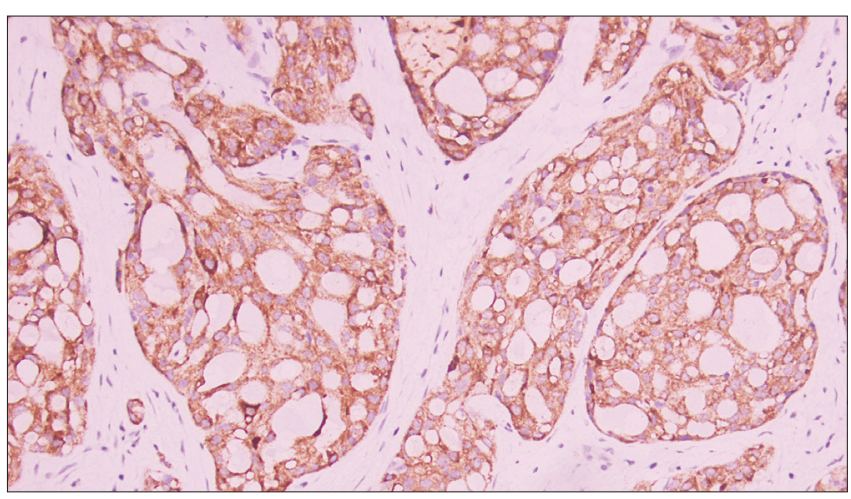

Figure 3. Epithelial membrane antigen positivity shown immunohistochemically in tumor cells

much poorer prognosis (5). Secretory carcinoma is usually a unifocal tumor but there are reports of multifocal cases (6).

Due to having a rather limited islet-like invasion pattern in microscopy, its cribriform-like adenoid structures and microcysts are easily confused with in situ carcinomas in needle biopsies.

Histochemical staining of the intraluminal material for PAS and immunohistochemical staining of tumor cells with S100 and EMA can be helpful in defining the diagnosis. The tumor is usually a triple- negative (ER, PR and HER2 negative) molecular subtype. Some portion of cases, including our case, can be weakly positive for ER. It is known that triplenegative phenotypes behave aggressively. In spite of having such features, the tumor's prognosis is highly favorable (1-3). In contrast to the tumor's molecular appearance, it has extremely good prognosis (1-3). The risk of developing systemic metastases is also extremely low $(1,2)$.

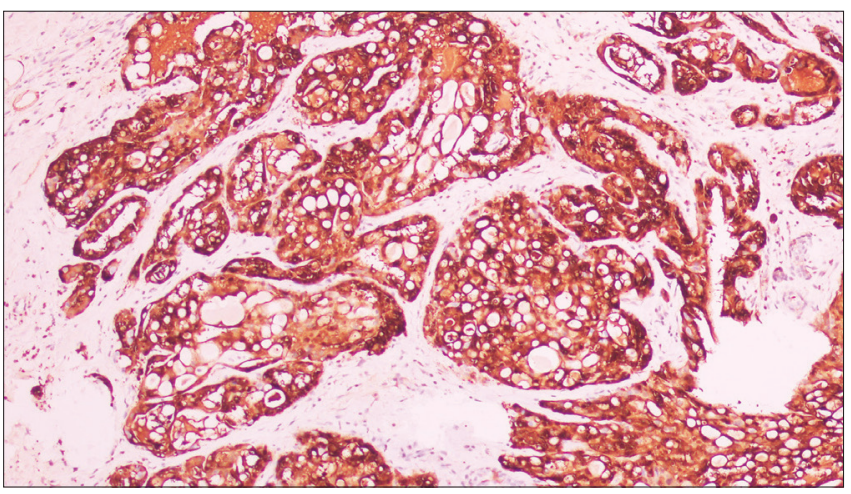

Figure 4. Immunohistochemical S100 protein positivity in tumor cells

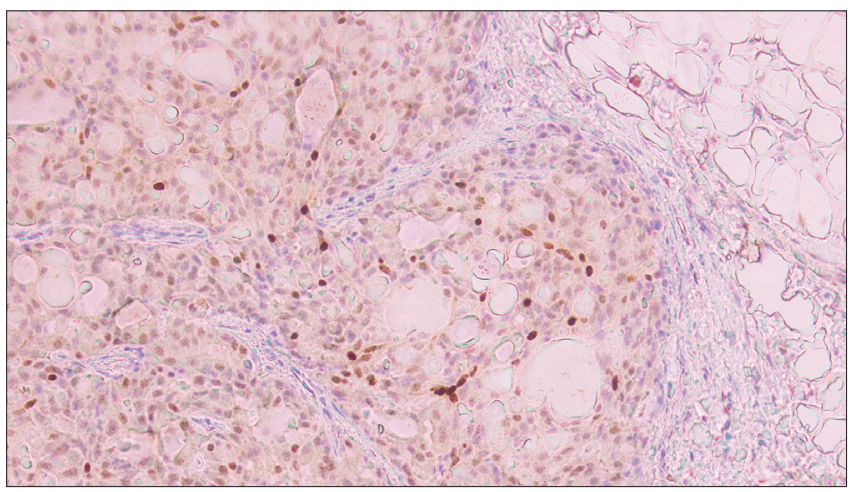

Figure 5. Positive nuclear staining for ER in tumor cells

It was recently demonstrated that these carcinomas develop due to $\mathrm{t}(12,15)$ ETV6-NTRK3 gene translocation (7). Interestingly, salivary gland tumors have been reported that were genetically and morphologically similar, thus getting the name of "mammary-analogue secretory carcinoma of salivary glands" (8). This tumor also has a good prognosis until it undergoes high-grade transformation. Drilon et al. demonstrated that pan-Trk inhibitor entrectinib (Ingyta) treatment had a dramatic clinical response when used as a targeted treatment (8). Breast secretory carcinoma is likely to have same anti-target therapy.

There are no reports of the combination of secretory carcinoma with fibroadenoma in the literature. However, the knowledge that this type of tumor and fibroadenomas are mostly seen in young adults increases the possibility of such a combination.

The primary treatment option for secretory carcinoma is surgery. Sentinel lymph node biopsy is recommended because the incidence of axillary metastases has been reported as $30 \%$ in patients with tumors larger than $2 \mathrm{~cm}$ (6). Our patient had a tumor of approximately $1 \mathrm{~cm}$ and no metastases in axilla.

A good knowledge of secretory breast carcinoma histologic diagnosis is important, especially to avoid possible mistakes in the needle biopsy.

Informed Consent: Written informed consent was obtained from patient.

Peer-review: Externally peer-reviewed.

Author Contributions: Concept - F.A., V.Ö.. Design - F.A., D.S..; Supervision - V.Ö.; Materials - F.A., D.S.; Data Collection and/or Processing - F.A., D.S.; Analysis and/or Interpretation - F.A., D.S.; Literature Review - F.A., D.S.; Writing - F.A., D.S.; Critical Review - V.Ö. 
Conflict of Interest: No conflict of interest was declared by the authors.

Financial Disclosure: The authors declared that this study has received no financial support.

\section{References}

1. Tavassoli FA. Secretory carcinoma. In: Tavassoli FA, Devilee P, editors. Pathology and Genetics of Tumors of the Breast and Female Genital Organs. World Health Organization Classification of Tumours. Vol. 4. Lyon, France: IARC Press; 2003. p. 42-3.

2. McDivitt R. W., Stewart F. W. Breast carcinoma in children, The Journal of the American Medical Association 1966; 5:388-390. [CrossRef]

3. Richard G, Hawk JC 3rd, Baker AS Jr, Austin RM. Multicentric adult secretory breast carcinoma: DNA flow cytometric findings, prognostic features, and review of the world literature. J Surg Oncol 1990: 44:238244. (PMID: 2200927). [CrossRef]
4. Sharma R, Singh S, Jaswal TS. Secretory carcinoma of bre ast in an elderly female. Indian J Pathol Microbiol. 2001; 44:449-450.

5. Kulkarni MM, Khandeparkar SG, Joshi AR, Dhande AN. A rare case of multicentric secretory carcinoma of breast in an adult female with review of literature. Indian J Pathol Microbiol 2016; 59:209-211. [CrossRef]

6. Li D, Xiao X, Yang W. Secretory breast carcinoma: a clinicopathological and immunophenotypic study of 15 caseswith a review of the literatüre. Mod Pathol 2012; 25:567-575. (PMID: 22157932). [CrossRef]

7. Arce C, Cortes-Padilla D, Huntsman DG, Miller MA, Dueñnas-Gonzalez A, Alvarado A, Pérez V, Gallardo-Rincón D, Lara-Medina F., Secretory carcinoma of the breast containing the ETV6-NTRK3 fusion gene in a male: case report and review of the literatüre. World J Surg Oncol 2005: 17:35. (PMID: 15963235). [CrossRef]

8. Drilon A, Li G, Dogan S, Gounder M, Shen R, Arcila M. What hides behind the MASC: clinical response and acquired resistance to entrectinib after ETV6-NTRK3 identification in a mammary analogue secretory carcinoma (MASC). Ann Oncol 2016; 15. (pi: mdw042). 